J. Amer. Soc. Hort. SCI. 116(4):701-705. 1991.

\title{
Predictive Model for Onset and Development of Internal Heat Necrosis of 'Atlantic' Potato
}

\author{
S.B. Sterrett ${ }^{1}$ \\ Eastern Shore Agricultural Experiment Station, Virginia Polytechnic Institute and State University, \\ Painter, VA 23420
}

G.S. Lee ${ }^{2}$

Arkansas Cooperative Extension Service, University of Arkansas, Little Rock AR 72203

M.R. Henninger ${ }^{3}$

Department of Horticulture, Cook College, Rutgers University, New Brunswick NJ 08903

M. Lentner ${ }^{3}$

Department of Statistics, Virginia Polytechnic Institute and State University, Blacksburg, VA 24061

Additional index wors. Solanum tuberosum, accumulated heat units, heat-sum model

Abstract. In 'Atlantic' potato (Solanum tuberosum L.) the onset and development of internal heat necrosis (IHN) varied with planting date and location in 1989. Symptoms of IHN (first trace) took fewer days to appear in the later plantings in Virginia and New Jersey. However, the interval from first trace to offgrade was extended in the later plantings. Data from successive harvests in these two locations over the past 4 years were used to develop a two-stage model to predict first trace and offgrade by stepwise regression techniques. The predictive model for first trace included rainfall and variables calculated from a heat-sum model that reflected maximum and minimum air temperatures during tuber initiation and early enlargement. The addition of variables reflecting size distribution and rainfall events at first trace resulted in a strong predictive model for offgrade $\left(R^{2}=0.98\right.$, Mallow's criterion $\left.=2.97\right)$. These models indicate that onset and development of IHN are influenced by environmental stress during more than one stage of growth. A delay in the development of offgrade tubers would be expected in years with a cool, wet spring, fewer tubers $>64 \mathrm{~mm}$ in diameter at first trace, and more rain events during the 10 days immediately after first trace.

In the mid-Atlantic region, 'Atlantic' is the potato cultivar of choice for the potato chip industry. This cultivar combines high yields and high specific gravity with acceptable chip color (Webb et al., 1979). However, 'Atlantic' is susceptible to the disorder commercially referred to as IHN. The first visible symptoms of IHN are generally small, localized areas of necrotic tissue in the parenchyma inside the vascular ring. IHN occurs first toward the apical end of the larger tubers in the hill (Henninger et al., 1979). As IHN progresses, the area affected and the color intensity of the necrotic tissue increase (Sterrett et al., 1991). The USDA no. 1 grade potato standards specify that total defects may not exceed $8 \%$, with internal defects not to exceed $5 \%$ by weight (U.S. Dept. of Agriculture, 1972). The occurrence of IHN in the largest tubers severely limits the percentage of tubers with IHN tolerated in a USDA no. 1 lot of potatoes.

Several studies have associated the incidence of necrotic tissue with above normal temperature and below normal rainfall (Friedman, 1955; Larson and Albert, 1945; Wolcott and Ellis, 1959). Sterrett et al. (1991) found a complex relationship between the progression of IHN, time (DAP), temperature, and rainfall.

In a recent grower survey in Virginia and North Carolina, $90 \%$ of the potatoes grown for processing in 1988 were 'Atlantic', and this cultivar was specified in $83 \%$ and $90 \%$ of the

\footnotetext{
Received for publication 16 Mar. 1990. Research supported in part by grants from Anheuser Busch Co., and Wise Foods-Bordon, Inc. We thank C.P. Savage, Jr., and F.W. Punk for their assistance in these studies. The cost of publishing this paper was defrayed in part by the payment of page charges. Under postal regulations, this paper therefore must be hereby marked advertisement solely to indicate this fact.

'Associate Professor.
}

${ }^{2}$ Extension Horticulturist-Vegetables.

${ }^{3}$ Professor. processing contracts in these two states, respectively (Sterrett and Wilson, 1990). Between 1986 and 1988, 3.2\% to $11.2 \%$ of 'Atlantic' acreage was left unharvested because tubers were out of USDA no. 1 grade (offgrade) as a result of IHN (Sterrett and Wilson, 1990). To meet chip processor demands for 'Atlantic' while minimizing the risk of economic loss from IHN, a predictive model is needed for use as a harvest scheduling tool. Reliable prediction of the onset and development of IHN would then facilitate the scheduling of harvest to optimize crop yield while limiting the adverse economic impact of IHN.

Many researchers have used growing-degree-day or heat-sum models to predict dry matter accumulation in potato (Dean et al., 1981; Hartz and Moore, 1978; Sands et al., 1979; Van Heemst, 1986). Iritani (1963) noted that maximum air temperatures $>29.4 \mathrm{C}$ during tuber initiation and early tuber development are detrimental to yield. Several heat-sum models have included an adjustment in accumulated heat units to reflect the detrimental effect of high daytime temperature on dry matter accumulation (Dean et al., 1981; Hartz and Moore, 1978; Van Heemst, 1986).

In the heat-sum model described by Dean et al. (1981) for growth of 'Russet Burbank', the adjustment of the heat-sum calculation was based on the relationship of temperature to specific growth responses, including sprout growth, emergence, vegetative growth, and rate of photosynthesis, but the calculation was modified when the air maximum exceeded $25 \mathrm{C}$. However, the adverse effects of excessive minimum temperatures are not reflected in the Dean model.

Environmental variables have been included in several predictive models assessing the effects of specific diseases on yield loss (James et al., 1972; Teng et al., 1979). Franc et al. (1989)

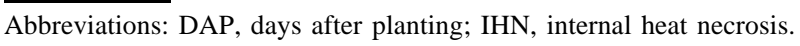


used a simple day-degree or heat-sum model to predict the appearance of early blight (Alternaria solani) lesions on potato foliage. However, little work has been done on the prediction of physiological disorders of potatoes. Therefore, we studied and report here on the onset and development of IHN in 'Atlantic' potato.

\section{Materials and Methods}

The studies were conducted at the Eastern Shore Agricultural Experiment Station, Painter, Va., and at the Rutgers Research and Development Center, Bridgeton, N. J., in 1986 through 1989. Cultural practices for trials in 1986 through 1988 have been described by Sterrett et al. (1991).

For each year at each location, the first appearance of trace IHN and offgrade potatoes (mean IHN rating $\leq 7$ for tubers $>64$ $\mathrm{mm}$ in diameter) were determined by successive harvests. In 1986, IHN was evaluated in two plantings in New Jersey. In 1989, three plantings in Virginia and three plantings in New Jersey were evaluated (Table 1). Cultural practices at each location in 1989 were consistent with those reported for the previous 3 years. Rainfall in excess of the 49 -year average delayed the 1989 Virginia plantings by almost 3 weeks. For all plantings, fertility levels included $\left(\mathrm{kg} \cdot \mathrm{ha}^{-1}\right) \quad 112 \mathrm{~N}-49 \mathrm{P}-93 \mathrm{~K}$ banded at plantings with $56 \mathrm{~kg} \mathrm{~N} / \mathrm{ha}$ sidedressed 6 to 7 weeks later. A randomized complete block design was used with four replications in Virginia and six in New Jersey (four in the late planting, 1986). Between-row spacing of $0.9 \mathrm{~m}$ and within-row spacing in Virginia and $0.23 \mathrm{~m}$ in New Jersey reflected commercial spacing in the two growing areas.

In 1989, plots $7.6 \mathrm{~m}$ long in Virginia and $7.3 \mathrm{~m}$ in New Jersey were mechanically harvested, sized, and evaluated for IHN as previously described for New Jersey (Sterrett et al., 1991). Severity of IHN was rated on a 1 to 9 subjective scale where $1=$ severe necrosis and $9=$ no visible symptoms.
Samples were considered offgrade when mean IHN rating was $\leq 7$.O for tubers $>64 \mathrm{~mm}$ in diameter.

Since the incidence and severity of IHN increases with successive harvests, the comparisons for IHN in 1989 were completed using a regression equation for each planting. The hypothesis that the progression of IHN was the same for all planting dates was investigated by testing the simultaneous equality of slopes and intercepts of the regression equations (Sterrett et al., 1991).

Stepwise regression techniques were used to develop predictive models for both first trace and offgrade potatoes. Data from both locations over 4 years (1986-1989) were included in the development of the predictive model. Planting dates, rainfall, and temperature variables are summarized in Table 1 . The heatsum model, of Lee and Sterrett (1989) was used to calculate the accumulated heat units for each growing season. The slope of that heat-sum line during the first 60 DAP (slope60) was calculated using regression analyses. Penalty was defined as the time in DAP of the first occurrence of three consecutive days of negative heat units.

A two-stage or forecasting type model evolved from the stepwise regression analyses. Variables included in the model to estimate first trace reflect environmental conditions to which the plants were exposed during the first 60 DAP. When first trace was established, variables associated with tuber size distribution and with temperature and rainfall during the 10 days after first trace were added to the 60 DAP variables to develop the predictive model for offgrade. The offgrade predictive model assumes that any given planting would eventually go offgrade.

Multi-colinearity from closely related temperature or rainfall variables was avoided by limiting the variables in any given model. The extent of multi-colinearity in the predictive models was assessed by a condition index in which a value $<100$ indicates minimal multi-colinearity and a condition index between 100 and 1000 implies moderate to strong collinearity (Montgom-

Table 1. Planting dates, date of first trace of IHN, offgrade tuber size distribution, and environmental characteristics used in stepwise regression.

\begin{tabular}{|c|c|c|c|c|c|c|c|}
\hline \multirow{2}{*}{$\begin{array}{l}\text { Planting } \\
\text { date }\end{array}$} & \multirow{2}{*}{$\begin{array}{c}\text { First } \\
\text { trace } \\
\text { (DAP) }\end{array}$} & \multirow{2}{*}{$\begin{array}{c}\text { Offgrade } \\
\text { (DAP) }\end{array}$} & \multirow{2}{*}{$\begin{array}{c}\text { Large } \\
\text { tubers } \\
(\%)^{z}\end{array}$} & \multicolumn{4}{|c|}{ Environmental characteristics ${ }^{y}$} \\
\hline & & & & Slope60 & Penalty & Nrain60 & NrainFT \\
\hline \multicolumn{8}{|c|}{ Virginia } \\
\hline 24 Mar. 1986 & 86 & 119 & $67^{\circ}$ & 3.85 & 67 & 11 & 2 \\
\hline 9 Apr. 1987 & 86 & 105 & 46 & 3.99 & 51 & 15 & 0 \\
\hline 30 Mar. 1988 & 91 & 122 & 59 & 3.87 & 59 & 23 & 3 \\
\hline 5 Apr. 1989 & 93 & 129 & 42 & 4.04 & 57 & 19 & 4 \\
\hline 14 Apr. 1989 & 89 & $137^{x}$ & 40 & 4.52 & 47 & 22 & 4 \\
\hline 24 Apr. 1989 & 79 & $127^{x}$ & 46 & 4.95 & 37 & 25 & 4 \\
\hline \multicolumn{8}{|c|}{ New Jersey } \\
\hline 2 Apr. 1986 & 98 & 133 & 28 & 2.25 & 58 & 10 & 3 \\
\hline 23 Apr. 1986 & 75 & 111 & 66 & 3.42 & 37 & 9 & 4 \\
\hline 12 Apr. 1987 & 93 & 117 & 28 & 3.12 & 46 & 11 & 0 \\
\hline 24 Mar. 1988 & 112 & 147 & 30 & 2.33 & 66 & 17 & 5 \\
\hline 29 Маг. 1989 & 111 & 136 & 21 & 2.69 & 64 & 16 & 3 \\
\hline 11 Apr. 1989 & 98 & 130 & 19 & 3.12 & 50 & 14 & 2 \\
\hline 21 Apr. 1989 & 88 & 125 & 23 & 3.08 & 39 & 17 & 3 \\
\hline
\end{tabular}

$z \%$ large $=$ percentage of tubers $>64 \mathrm{~mm}$ diameter at first trace.

ySlope60 $=$ slope of regression line of accumulated heat unit over time (DAP) during the first 60 days. Penalty = Time (in days) from planting to 3 consecutive days of negative heat units greater than -0.01 . Nrain $60=$ rain events during 1 to 60 DAP. NrainFT = rain events during 10 days after first trace.

xLast harvest for each planting. Rating of IHN was 7.8 and 8.0 on a 9-point scale for the 14 and 24 Apr. plantings, respectively. $9=$ no visible symptoms, $1=$ severe necrosis. 
Table 2. Regression equations used to predict onset of IHN (first trace and offgrade).

\begin{tabular}{|c|c|c|c|c|}
\hline Dependent variable & Independent variables ${ }^{z}$ & $R^{2}$ & $C(p)^{y}$ & $\begin{array}{c}\text { Bounds on } \\
\text { condition } \\
\text { number }\end{array}$ \\
\hline $\begin{array}{l}Y_{\text {First trace }} \\
Y_{\text {Offgrade }} \\
\end{array}$ & $\begin{array}{l}=90.62-11.00 \mathrm{X}_{\text {Slope } 60}+1.08 \mathrm{X}_{\text {Nrain60 }}+0.43 \mathrm{X}_{\text {Penalty }} \\
=113.31+0.51 \mathrm{X}_{\text {Penalty }}-38.29 \mathrm{X}_{\% \text { large }}+3.75 \mathrm{X}_{\mathrm{NrainFT}}\end{array}$ & $\begin{array}{l}0.855^{* *} \\
0.981^{* *}\end{array}$ & $\begin{array}{l}4.33 \\
2.97\end{array}$ & $\begin{array}{r}14.10 \\
9.32 \\
\end{array}$ \\
\hline
\end{tabular}

${ }^{2}$ Penalty $=$ DAP (see Table 1) to negative accumulated heat units: Slope $60=$ slope of regression line of accumulated heat unit
over time (DAP) during the first 60 .

$>64 \mathrm{~mm}$ at first trace; NrainFT $=$ number of rain events during 10 days after first to $60 \mathrm{DAP} \% \%$ large = percentage of tubers

yMallow's criterion, a measure of total squared events during 10 days after first trace.

xA.measure of multi-colinearity (SAS, 1985; Morror (SAS, 1985).

${ }^{* *}$ Significant at $\alpha=0.01$.
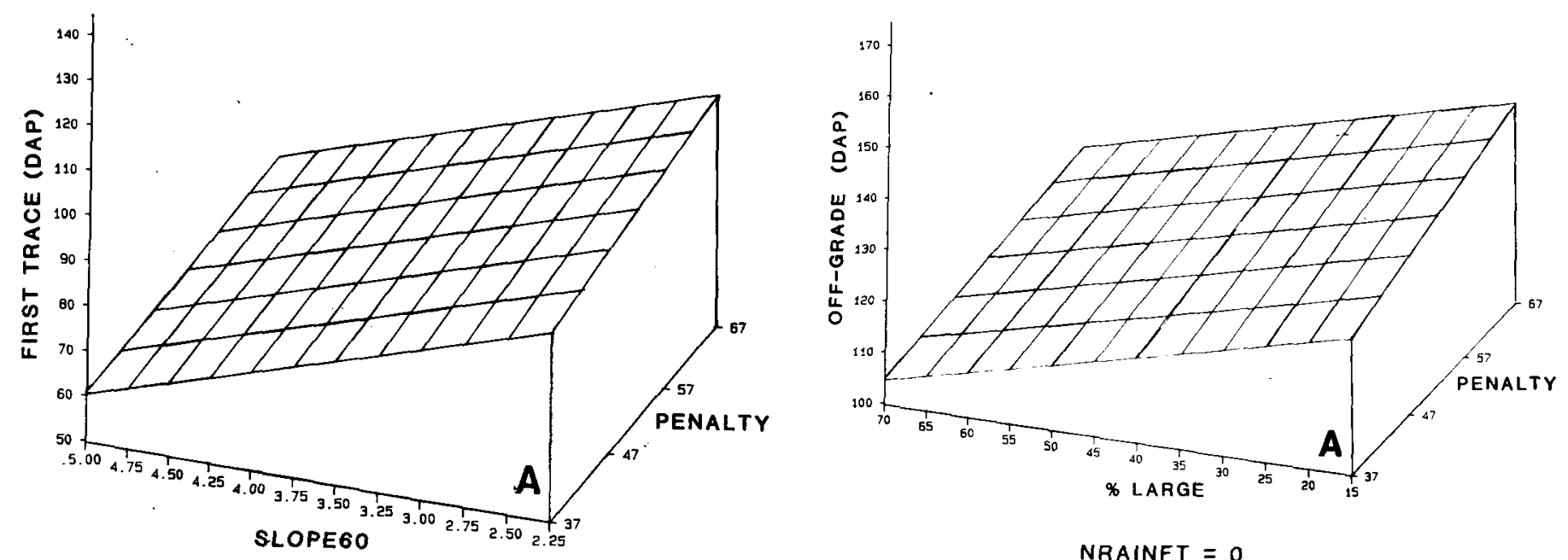

NRAINGO $=9$
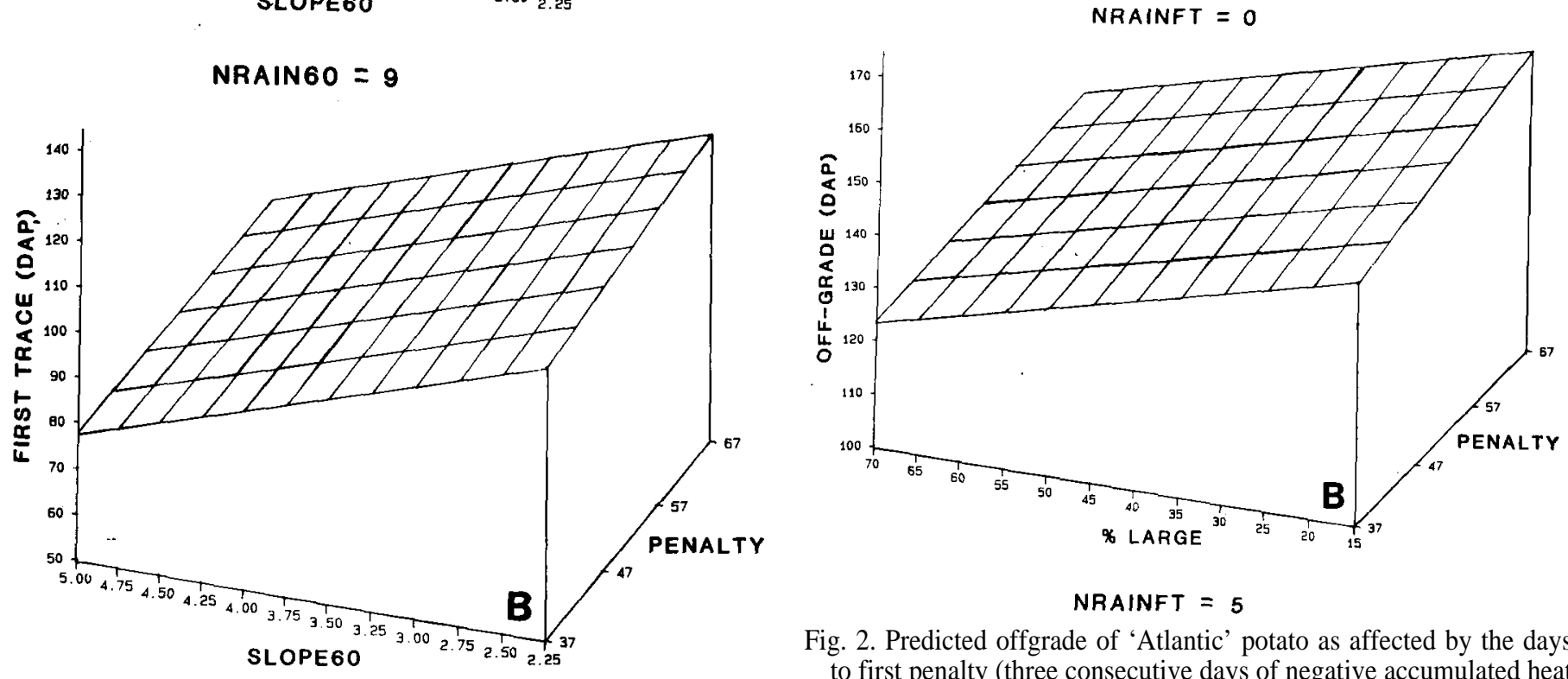

Fig. 2. Predicted offgrade of 'Atlantic' potato as affected by the days to first penalty (three consecutive days of negative accumulated heat units), and yield distribution (\% large) with zero (A) or five (B) rain events in the 10 days immediately after first trace. $\%$ large $=$ percentage of tubers $>64 \mathrm{~mm}$ diameter.

\section{Results and Discussion}

Fig. 1 Predicted first trace of 'Atlantic' potato as affected by the slope of the accumulated heat unit equation for the first 60 DAP and the days to first penalty (three consecutive days of negative accumulated heat units), with nine (A) or 25 (B) rain events during the first 60 DAP.

ery and Peck, 1982). The "Bounds on condition number" calculated in the stepwise regression procedure of SAS is the square root of this condition index (SAS, 1985). In the selection of variables for inclusion in the predictive models, 15 was the maximum acceptable Bounds on condition number.

J. Amer. Soc. Hort. Sci. 116(4):701-705. 1991. 

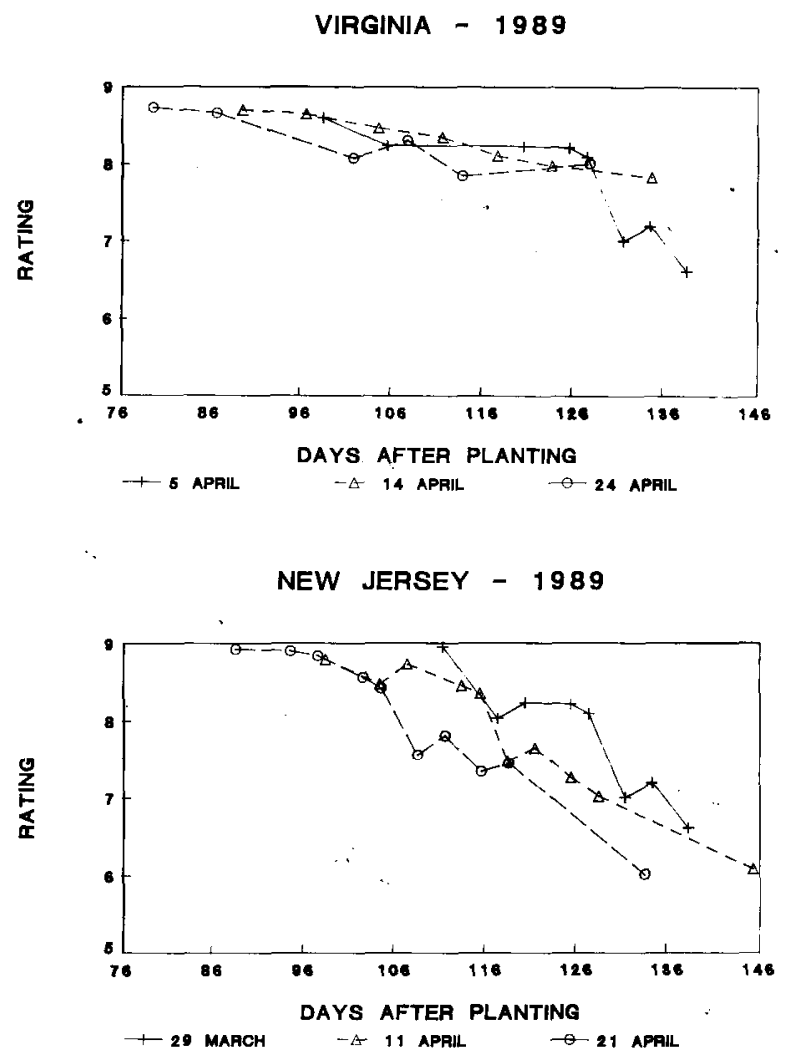

Fig. 3. Comparison of the progression of IHN over two locations and three plantings in 1989. The length of each line represents interval from first trace to offgrade.

gomery and Peck, 1982)] as well as providing a good fit $\left(R^{2}=\right.$ 0.855) of the data. Heat units accumulated more slowly in a cool spring, and the slope during the first 60 days approached 2.0 , resulting in a delay in first trace (Fig. 1). Extending the number of DAP until the penalty occurred also delayed first trace. The onset of IHN was further delayed by increasing the number of rain events during the first 60 DAP. Since the penalty was invoked when the air maximum or minimum exceeded $25 \mathrm{C}$ or $21 \mathrm{C}$, respectively, the appearance of first trace was hastened by a warm, dry spring with an early period of high temperatures $(>25 \mathrm{C})$ lasting 3 or more days.

Combining penalty with the percentage of tubers $>64 \mathrm{~mm}$ at first trace, and the number of rain events during the 10 days after first trace (NrainFT) resulted in a strong predictive model for offgrade. The regression equation for offgrade (Table 2) closely fit the observed data $\left(R^{2}=0.981\right)$. Both the low Mallow's criterion and "Bounds on condition number" indicated a strong predictive equation. The complex model indicated that the severity of IHN was influenced by the maximum-minimum temperature patterns during tuber initiation and early enlargement (60 DAP), factors affecting tuber size distribution and the environmental conditions occurring immediately after first trace. As with first. trace, extending the number of DAP before a penalty occurred delayed offgrade (Fig. 2). As the number of rain events in the 10 days after first trace increased, offgrade was further delayed.

Several early studies associated increased necrosis with drought late in the growing season (Ellison and Jacob, 1952; Friedman, 1955; Wolcott and Ellis, 1959). Wolcott and Ellis (1959) also noted an increase in necrosis in growing seasons when fewer tubers were set per hill. Stewart et al. (1981) noted that con- ditions most conducive to the formation of tubers included short days and low temperature (12C). In our study, the predictive models for first trace and offgrade indicate that low temperatures early in the growing season were also conducive to delaying the onset of IHN. As the variable "penalty" reflects the effect of maximum and minimum temperatures during tuber initiation and early tuber growth, the rain events after the first visible symptoms of IHN (NrainFT) reflect the effects of environmental stress later in the growing season, during tuber bulking. The inclusion of rain events in the models suggests the possible influence of reduced light intensity, reduced temperatures, or increased relative humidity associated with rain on photosynthesis, respiration, or other physiological processes. However, neither total rainfall nor irrigation contributed significantly to either model.

In Virginia and New Jersey in 1989, moderate temperatures and above-average rainfall occurred during July and August. In Virginia in 1989, the first planting became offgrade 7 to 24 days later than in previous years (Sterrett et al., 1991). Symptoms of IHN appeared earlier (fewer DAP) in the later plantings at both locations in 1989 (Fig. 3, Table 1) but the interval from first trace to offgrade was extended, The average rating for the second and third plantings in Virginia did not drop below 7.0, even though successive harvests of these plots continued 3 weeks after commercial harvesting was complete. The onset and development of IHN in New Jersey in 1989 followed a similar pattern to that reported for 1988, with onset occurring late in the season and offgrade occurring toward the end of the commercial harvest period.

While the offgrade model was based on the assumption that all plantings would go offgrade, two plantings in Virginia in 1989 did not. However, the predicted date of offgrade for each of these plantings was $>2$ weeks past the end of the usual harvest period (July-early August) for Virginia. This estimate of a prolonged interval before offgrade indicates a reduced risk of IHN for that planting, so that harvest could be scheduled accordingly. The use of these models in the prediction of both onset of IHN and offgrade would facilitate the timely scheduling of harvest to minimize risk of economic loss and maximize crop yield.

Yearly variation in the expression of IHN has been well documented (Ellison and Jacob, 1952; Friedman, 1955; Larson and Albert, 1945, 1949). Ellison and Jacob (1952) also reported differences in susceptibility of tubers to IHN with planting date. Ellison and Jacob (1952) associated susceptibility to IHN with specific periods of that exceeded a 33C weekly mean maximum, suggesting a period of peak susceptibility. Wolcott and Ellis (1959) related susceptibility to IHN to elevated temperature and drought, but noted that susceptibility was also affected by tuber size. In their study of 20 cultivars, IHN was less severe in 1954 when the number of tubers set per hill was high and tuber size smaller than in the previous year. In Virginia and New Jersey, first trace was frequently observed before the occurrence of a 33C maximum, suggesting that the environmental conditions conducive to the onset of IHN occurred during the earlier growth stages. The differences noted in the progression of IHN in 1989 with delayed planting may be due, in part, to differences in the physiological age of the developing tubers when the environmental conditions were conducive to the onset of IHN.

These studies of IHN have focused on the influence of environmental stress after planting. The data indicate that economic loss from IHN is greater in those years with relatively high temperatures during the first 60 DAP, particularly with an 
early period of 3 or more days $>25 \mathrm{C}$. A dearth of rain events during tuber initiation and early development (60 DAP) and after first trace hastens the development of IHN. Economic loss also increases with environmental or physiological conditions conducive to a low tuber set with a correspondingly larger eventual tuber size.

\section{Literature Cited}

Dean, R.B., R.E. Thornton, and R.A. Kennedy. 1981. Effect of environment on dry matter of potato tubers. Proc. Wash. State Potato Conf. 20:67-72.

Ellison, J.H. and W.C. Jacob. 1952. Internal browning of potatoes as affected by date of planting and storage. Amer. Potato J. 29:241252.

Franc, G.D., M.D. Harrison, and L.K. Lohman. 1989. A simple daydegree model for initiating chemical control of potato early blight in Colorado. Plant Dis. 72:851-854.

Friedman, B.A. 1955. Association of internal brown spot of potato tubers with hot, dry weather. Plant Dis. Rptr. 39(1):37-44.

Hartz, T.K. and F.D. Moore, III. 1978. Prediction of potato yield using temperature and insolation data. Amer. Potato J. 55:431-436.

Henninger, M.R., J.W. Patterson, and R.E. Webb. 1979. Tuber necrosis in 'Atlantic'. Amer. Potato J. 56:464. (Abstr.)

Iritani, W.M. 1963. The effect of summer temperatures in Idaho on yield of Russet Burbank potatoes. Amer. Potato J. 40:47-52.

James, W.C., C.S. Shih, W.A. Hodgeson, and L.C. Callbeck. 1972. The quantitative relationship between late blight of potato and loss in tuber yield. Phytopathology 62:92-96.

Larson, R.H. and A.R. Albert. 1945. Physiological internal necrosis of potato tubers in Wisconsin. J. Agr. Res. 41:487-505.

Larson, R.H. and A.R. Albert. 1949. Relation of potato varieties to incidence of physiological internal tuber necrosis. Amer. Potato J. $16: 427-431$.
Lee, G.S. and S.B. Sterrett. 1989. Heat-sum model to determine yield and onset of heat necrosis for 'Atlantic' potatoes. Amer. Potato J. (In press.)

Montgomery, D.C. and E.A. Peck. 1982. Introduction to linear regression analysis. Wiley, New York.

Sands, P.J., C. Hackett, and H.A. Nix. 1979. A model of the development and bulking of potatoes (Solanum tuberosum L.). I. Derivation from well-managed field crops. Field Crops Res. 2:309-331.

SAS Institute, Inc. 1985. SAS user's guide: Statistics. SAS Institute, Inc., Cary, N.C.

Sterrett, S.B. and G.L. Wilson. 1990. Internal heat necrosis in 'Atlantic': A survey of the disorder. Veg. Growers News 44(4):2, 4.

Sterrett, S.B., M.R. Henninger, and G.S. Lee. 1991. Relationship of internal heat necrosis of potato to time and temperature after planting. J. Amer. Soc. Hort. Sci. 116:697-700.

Stewart, F.C., U. Moreno, and W.M. Roca. 1981. Growth, form, and composition of potato plants as affected by environment. Ann. Bot. Suppl. 2:1-45.

Teng, P.S., R.C. Close, and M.J. Black. 1979. A comparison of models for estimating yield loss caused by leaf rust (Puccinia hordeiOtth) on Zephyr barley in New Zealand. Phytopathology 69:12391244.

U.S. Department of Agriculture. 1972. United States standards for grades of potatoes. U.S. Dept. Agr. Mktg. Serv. 35 F.R. 18257.

Van Heemst, H.D.J. 1986. The distribution of dry matter during growth of a potato crop. Potato 29:55-56.

Webb, R.E., D.R. Wilson, J.R. Shumaker, B. Graves, M.R. Henninger, J. Watts, J.A. Frank, and H.J. Murphy. 1979. Atlantic: A new potato variety with high solids, good processing quality and resistance to pests. Amer. Potato J. 55:141-145.

Wolcott, A.R. and N.K. Ellis. 1959. Internal browning of potato tubers: Varietal susceptibility as related to weather and cultural practice. Amer. Potato J. 36:394-403. 